\title{
Rancang Bangun Pengelolaan Lab berbasis Firebase Cloud Messaging dan Motion Detection Camera menggunakan Raspberry Pi
}

\author{
Arsito Ari Kuncoro ${ }^{1}$, Edy Noriyanto ${ }^{2}$, Febryantahanuji ${ }^{3}$ \\ ${ }^{1}$ Sistem Komputer STEKOM Semarang \\ arsito@stekom.ac.id \\ ${ }^{2}$ Sistem Komputer STEKOM Semarang \\ edinoriyanto@gmail.com \\ ${ }^{3}$ Komputerisasi Akuntansi STEKOM Semarang \\ febryan@stekom.ac.id \\ JI. Majapahit 605, Semarang, telp/fax : 024-6717201-02
}

\section{ARTICLE INFO}

Article history:

Received 30 November 2019

Received in revised form 2 Desember 2019

Accepted 10 Desember 2019

Available online 12 Desember 2019
Security aspects is needed in various fields of life today. Safety is becoming a concern for everyone. One of the important concerns is the security of the room. The indoor security system uses Raspberry Pi and RFID based Firebase Cloud Messaging and Motion Detection Camera, is a room security system that includes expensive equipment, so this device is designed for protection or robbery and also provides assistance in advance. . The security system in this room consists of several parts, namely Raspberry Pi as a brain system, selenoid door lock as an electric lock on the door, RFID system and CCTV camera as a detector of the amount of human movement, PIR sensor as a detector of human temperature, alarm as an indicator of intruders which transfers rooms, and database applications as user storage databases for security recorders

Keywords: Raspberry Pi, Fingerprint, PIR, Firebase,

Messaging, Selenoid Door Lock, Motion Detection, Servo, Internet of Things, Information Management

\section{ABSTRACT}

\section{PENDAHULUAN}

Perkembangan teknologi saat ini sangat pesat khususnya dibidang komputerisasi dan elektronika. Teknologi yang dikembangkan bertujuan untuk memberikan keamanan, baik keamanan diri maupun keamanan terhadap barang-barang berharga dan dokumen-dokumen penting agar terhindar dari tindak kriminalitas, khususnya tindakan pencurian. Barang-barang dan dokumen-dokumen penting biasanya disimpan dalam suatu ruangan khusus agar tidak diambil oleh orang-orang yang tidak berhak. Menanggulangi hal tersebut, pihak perusahaan maupun instansi harus menambah pengeluaran untuk membayar sejumlah petugas penjaga pintu.

Sangat berarti sekali jika proses pengawasan pintu dibantu dengan penerapan teknologi, agar efisiensi dan proses pengawasannya lebih terstruktur dan lebih baik. Keamanan sebuah ruangan menjadi faktor penting dalam melakukan pengamanan tersebut. Lemahnya sistem keamanan ruang yang diberikan untuk menjaga barang-barang atau peralatan berharga serta dokumen-dokumen penting tersebut, memberikan peluang dan kesempatan pada orang lain yang tidak berkepentingan dan tidak berhak mengambil dan mencuri barangbarang yang terdapat di dalamnya, menerangkan bahwa pada tahun 2017 jumlah kejahatan terhadap hak milik/barang dengan kekerasan ataupun tidak dengan kekerasan disejumlah provinsi di indonesia 
khususnya di provinsi daerah jawa tengah di nilai tingkat kejadian kejahatan masih lumayan tinggi dengan dibuktikan dengan grafik angka kriminalitas pencurian sebagai berikut.

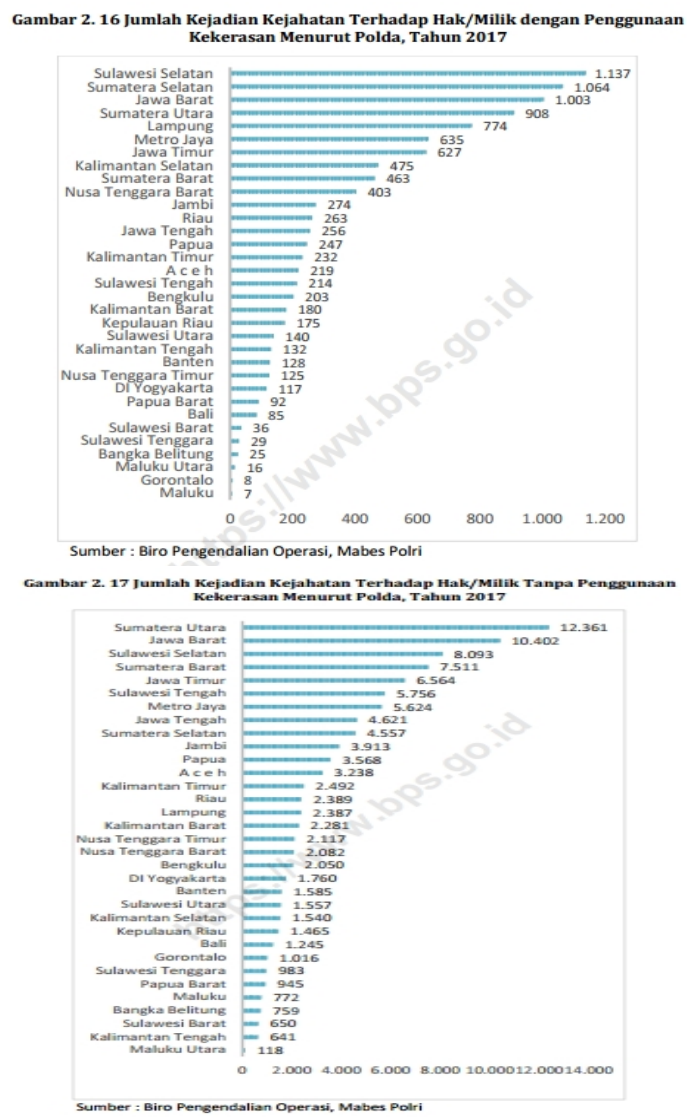

Gambar 1. Jumlah Kejadian Pencurian Kejahatan Terhadap Hak/Milik

Dari berita kasus tersebut maka sangatlah perlu untuk membangun sebuah alat sistem pengaman yang dapat diterapkan di lab.komputer sebuah sekolah menengah atas yang bertujuan untuk mencegah tindakan pencurian juga untuk membatasi akses siapa saja yang diperbolehkan untuk masuk dan menggunakan ruangan lab.komputer, agar lebih terjaganya kondisi ruang lab.komputer beserta peralatan yang ada didalamnya. Alasan untuk menerapkan sistem keamanan tersebut yaitu dari pengamatan peneliti tentang kondisi ruangan lab.komputer ditemukan beberapa kelemahan dari ruang lab tersebut yaitu pada tingkat keamanannya dinilai masih cukup minim atau rendah karena dari segi keamanan pintu dan jendelanya pun masih menggunakan pengaman manual atau kunci yang biasa sebagai pengaman untuk melindungi barangbarang dan alat perlengkapan didalamnya sehingga masih sangat mudah untuk dicongkel atau di bobol oleh pencuri. Sering kali ada beberapa peralatan acessories perlengkapan komputer banyak yang hilang seperti RAM, Mouse, Keyboard dan lainya yang mungkin saja diambil atau dipakai oleh orang yang tidak bertanggung jawab karena kondisi akses ruang lab.komputer yang masih dengan bebasnya untuk keluar masuk guru, karyawan dan murid yang tidak berkepentingan untuk menggunakan ruang lab.komputer tersebut. Sehingga untuk mengantisipasi hal-hal yang tidak diinginkan seperti tindak pencurian atau pembobolan maka sangatlah perlu untuk di bangunlah sebuah alat keamanan, salah satunya adalah sistem keamanan dengan menggunakan alat seperti Fingerprint, Camera pendeteksi gerakan manusia dan juga menggunakan Raspberry $P i$ yang merupakan salah satu perkembangan dari perangkat kendali mikrokontroler saat ini. 


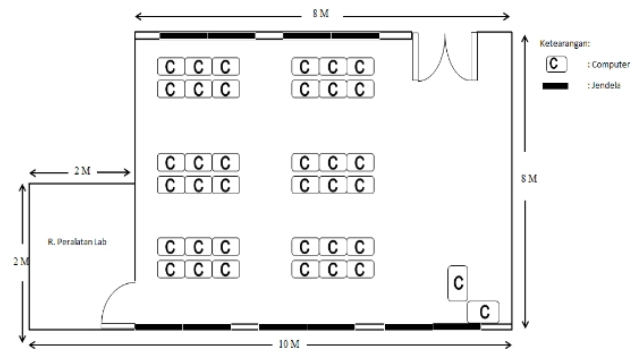

Gambar 2. Denah Ruang Lab. Komputer Sekolah Menengah Atas.

Dengan latar belakang dan pertimbangan tersebut serta dari memikirkan teknologi sistem keamanan yang dapat mengawasi tindak pencurian dan dapat membantu kegiatan manusia menjadi lebih mudah dan praktis, maka penelitian ini akan membuat sebuah alat keamanan akses ruangan menggunakan Raspberry $P i$ dan Fingerprint berbasis Firebase Cloud Messaging dan Motion Detection Camera. Sistem keamanan ruangan yang dibuat terdiri dari perangkat hardware dan software yang saling terintegrasi satu sama lain. Dengan Raspberry Pi sebagai pengendali sistem, solenoid door lock sebagai kunci elektrik pada pintu, Fingerprint System dan kartu tag Fingerprint sebagai alat pendeteksi sidik jari atau karyawan setiap user yang diperbolehkan untuk masuk menggunakan ruangan lab.komputer tersebut, Camera Module sebagai alat pendeteksi adanya gerakan manusia yang selanjutnya akan diteruskan disimpan dalam sebuah Real Time Database berupa Firebase Cloud Messaging yang dilengkapi dengan sistem Notifikasi Real Time yang memberikan notifikasi ke perangkat Android milik pengelola. Adapun penelitian yang menyatakan bahwa penggunaan smartphone android dapat mempermudah penyampaian informasi terhadap pengguna [1]

\section{TINJAUAN PUSTAKA}

\section{A. KAJIAN PENELITIAN}

Pada penelitian yang berjudul Perancangan Object Tracking Robot Berbasis Image Processing Menggunakan Raspberry Pi menerangkan bahwa proses ini dapat memberikan kemampuan pada computer untuk mengetahui gerakan suatu objek tertentu [2], berikut juga terdapat penelitian dengan judul Sistem Keamanan Berlapis Pada Ruangan Rfid (Radio Frequency Identification) Dan Keypad Untuk Membuka Pintu Secara Otomatis di dalam penelitian ini bertujuan untuk memberikan pengamanan pada ruangan dan akan bekerja mendeteksi keberadaan penyusup, secara otomatis membunyikan alarm ketika ada penyusup masuk [3]

Dari kedua penulis jurnal tersebut mengenai sistem keamanan pintu ruangan tersebut sama-sama menggunakan RFID namun disini masih ditemui adanya kelemahan pada masing-masing produk yang dikembangkan yaitu menggunakan RFID $125 \mathrm{KHz}$ yang mempunyai jarak baca dan kecepatan rendah dan alarm buzzer yang mempunyai tegangan dibawah $12 \mathrm{~V}$ juga masih menggunakan database mikrokontroler. Maka daripada itu peneliti ingin mengembangkan sebuah sistem alat keamanan pintu ruangan yang tingkat keamanannya lebih tinggi lagi untuk tingkat keamanannya dari produk peneliti sebelumnya yaitu dengan menggunakan alat Raspberry Pi, Fingerprint dan Raspberry Camera sebagai pendeteksi gerakan manusia serta dapat mengirimkan notifikasi pesan langsung ke Android pengelola.

\section{B. Raspberry Pi}

Raspberry Pi adalah sebuah SBC (Single Board Computer) seukuran kartu kredit yang dikembangkan oleh Yayasan Raspberry Pi di inggris (UK) dengan maksud untuk memicu pengajaran ilmu komputer dasar di sekolah-sekolah. Jika Raspberry $P i$ adalah jaringan, anda dapat mengontrol perangkat yang terhubung padanya dari mana saja (Tidak secara harfiah di mana saja, tentu saja. Anda perlu hal-hal seperti akses ke jaringan, jaringan yang mampu perangkat komputasi, dan listrik.) dan perangkat-perangkat dapat mengirim data kembali. Konektivitas dan kontrol dan perangkat fisik melalui internet adalah hal yang sangat kuat dan menarik, dan Raspberry Pi ideal untuk ini [4]

\section{METODE PENGEMBANGAN}

Metode penelitian dan pengembangan ( Research and Development ) adalah metode penelitian yang digunakan untuk menghasilkan produk tertentu, dan menguji keefektifan produk tersebut. 
metode penelitian dan pengembangan atau dalam bahasa Inggrisnya Research and Development adalah metode penelitian yang digunakan untuk menghasilkan produk tetentu, dan menguji keefektifan produk tersebut [5]

Dalam penelitian ini prosedur pengembangan yang digunakan mengacu pada penelitian Research and Development (R\&D). Menurut Sugiyono langkah-langkah penelitian R\&D terdiri dari 10 langkah, namun hanya 6 langkah saja yang digunakan dalam pengembangan produk.

\section{HASIL DAN PEMBAHASAN}

\section{A. Hasil Pengembanganan}

Hasil pengembangan "Sistem Keamanan Akses Ruang Lab berbasis Firebase Cloud Messaging dan Motion Detection Camera menggunakan Raspberry Pi dan Fingerprint “ yang dilakuakn menggunakan metode Research and Development (R\&D) telah menghasilkan sebuah prototype sistem keamanan.

\section{B. Pengujian Fingerprint Module}

Pengujian pada fingerprint module bertujuan untuk mengidentifikasi sidik jari yang telah terdaftar dan mampu membuka kunci pintu secara otomatis.

Berikut adalah tabel pengujian sidik jari pada Fingerprint Module sampai kunci pintu terbuka :

Tabel 1 Pengujian Sidik Jari Pada Fingerprint Module Oleh User/Pengguna

\begin{tabular}{|c|c|c|}
\hline No & Posisi Jari & $\begin{array}{c}\text { Status } \\
\text { Pintu }\end{array}$ \\
\hline 1 & Ibu Jari & Terbuka \\
\hline 2 & Ibu Jari & Terbuka \\
\hline 3 & Ibu Jari & Terbuka \\
\hline 4 & Ibu Jari & Terbuka \\
\hline 5 & Ibu Jari & Terbuka \\
\hline 6 & Ibu Jari & Terbuka \\
\hline 7 & Ibu Jari & Terbuka \\
\hline 8 & Ibu Jari & Terbuka \\
\hline 9 & Ibu Jari & Terbuka \\
\hline 10 & Ibu Jari & Terbuka \\
\hline
\end{tabular}

Dari hasil pengujian melalui beberapa user pengguna dapat di ketahui dari hasil tabel pengujian di atas bahwa sensor sidik jari yang digunakan dapat mengidentifikasi sidik jari (ibu jari) yang didaftarkan, dengan menempelkan sidik jari tersebut hasil yang di dapatkan status pintu dapat terbuka.

\section{Pengujian Camera, PIR}

Pengujian pada camera dan PIR bertujuan untuk memastikan camera dan PIR berfungsi dengan baik pada saat ada pendeteksian objek yang di tangkap. Berikut adalah pengujian camera dan PIR dari berbagai sudut :

Tabel 2. Pengujian Pendeteksi Objek Camera dan PIR

\begin{tabular}{|c|c|}
\hline Jarak (Meter) & $\begin{array}{c}\text { Jarak Deteksi } \\
\text { Camera dan PIR } \\
\text { Terhadap Manusia }\end{array}$ \\
\hline 1 & Terdeteksi \\
\hline 2 & Terdeteksi \\
\hline 3 & Terdeteksi \\
\hline
\end{tabular}


Dari hasil pengujian camera camera dapat bekerja dengan sampai 8 meter terhadap objek

\section{Pembahasan Produk}

\begin{tabular}{|c|c|}
\hline 4 & Terdeteksi \\
\hline 5 & Terdeteksi \\
\hline 6 & Terdeteksi \\
\hline 7 & Terdeteksi \\
\hline 8 & Terdeteksi \\
\hline
\end{tabular}

dan PIR di dapatkan hasil bahwa baik dengan jarak deteksi 1 manusia.

\section{Akhir}

Produk akhir yang dihasilkan dari pengembangan penelitian oleh penulis dengan menggunakan metode Research and Development (R\&D) telah terbangun suatu prototype berupa "Sistem Keamanan Akses Ruang Lab berbasis Firebase Cloud Messaging dan Motion Detection Camera menggunakan Raspberry P $i$ dan Fingerprint".

\section{Tampilan Login Aplikasi SIMOLA}

Adapun tampilan untuk admin masuk pada aplikasi smartphone android sebagai berikut:

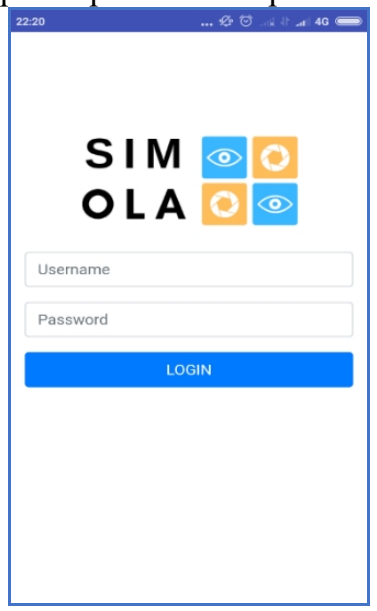

Gambar 3. Tampilan Login Aplikasi SIMOLA Pada Smartphone Android

Gambar di atas menunjukan tampilan awal ketika admin melakukan login pada aplikasi simola dengan memasukan username dan password yang telah di daftarkan.

\section{Tampilan Menu Aplikasi SIMOLA}

Adapun tampilan aplikasi setelah admin berhasil masuk/login pada smartphone android adalah sebagai berikut:

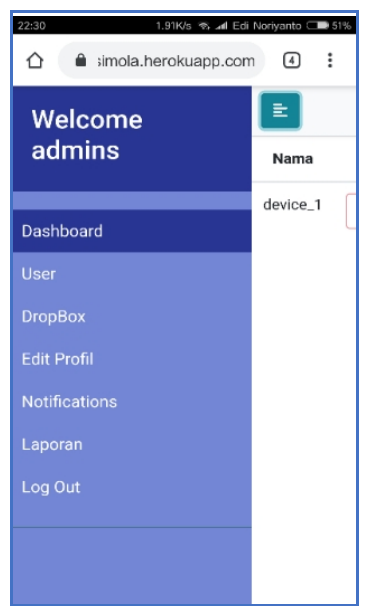

Gambar 4. Tampilan Menu Aplikasi SIMOLA Pada Smartphone Android

Gambar di atas adalah tampilan menu aplikasi simola yang terdapat beberapa fitur daftar menu-menu yang dapat di gunakan oleh admin untuk pengelolaan akun aplikasi. 
3. Tampilan Menu User Aplikasi SIMOLA

Adapun tampilan setelah menu user di buka adalah sebagai berikut :

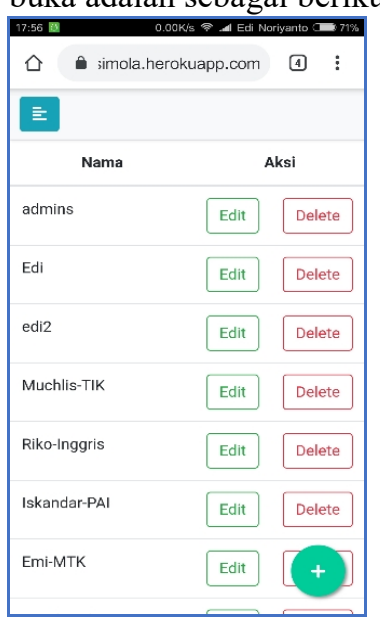

Gambar 5. Tampilan Menu User Aplikasi SIMOLA Pada Smartphone Android

Gambar di atas adalah tampilan dimana menu user ketika di pilih dan terdapat daftar nama user-user yang telah di daftarkan sidik jarinya pada alat simola.

\section{Tampilan Menu Dropbox Aplikasi SIMOLA}

Adapun tampilan menu dropbox setelah dibuka adalah sebgai berikut :

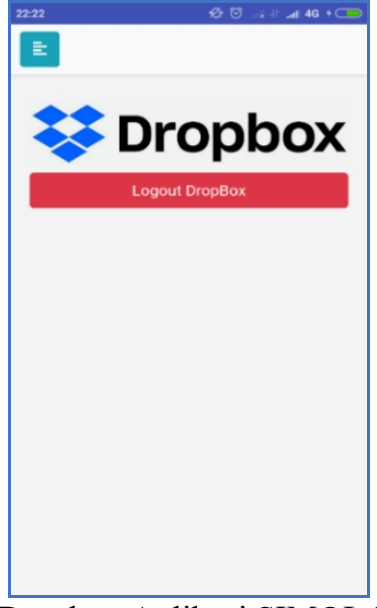

Gambar 6. Tampilan Menu Dropbox Aplikasi SIMOLA Pada Smartphone Android

Gambar di atas menunjukan ketika admin membuka menu dropbox untuk melihat hasil gambar deteksi yang telah ditangkap oleh kamera pada alat simola. 
7

\section{Tampilan Menu Edit Profil Aplikasi SIMOLA}

Adapun tampilan menu edit profil setelah di buka adalah sebagai berikut :

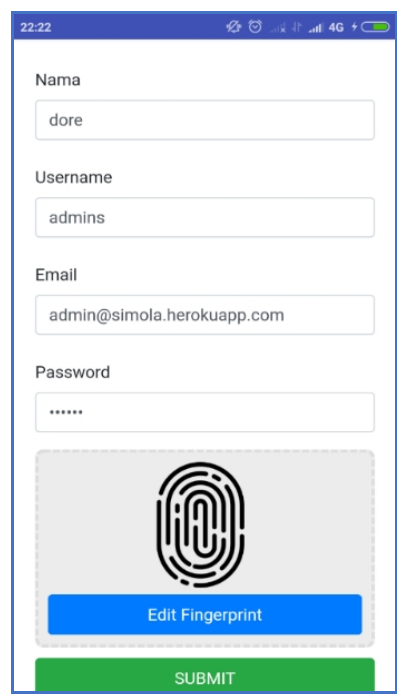

Gambar 7. Tampilan Menu Edit Profil Aplikasi SIMOLA Pada Smartphone Android Gambar di atas menujukan tampilan menu untuk mengedit user profil pengguna alat simola.

\section{Tampilan Menu Notifikasi Aplikasi SIMOLA}

Adapun tampilan dari menu notifikasi setelah di buka adalah sebagai berikut:

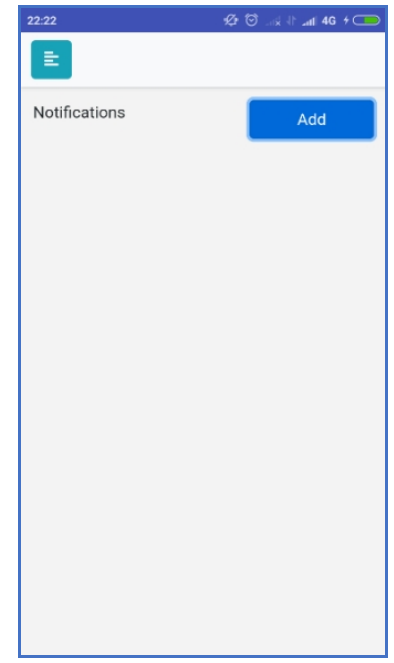

Gambar 8. Tampilan Menu Notifikasi Aplikasi SIMOLA Pada Smartphone Android Gambar di atas menunjukan tampilan menu notifikasi untuk mengedit tampilan pesan yang dikirimkan pada smartphone admin sebagai tanda ada penyusup yang telah terdeteksi alat simola.

\section{Tampilan Menu Laporan Aplikasi SIMOLA}

Adapun tampilan dari menu laporan setelah di buka adalah sebagai berikut: 


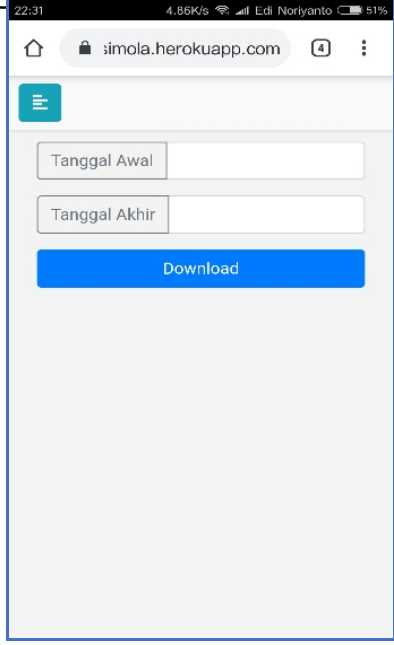

Gambar 9. Tampilan Menu Laporan Aplikasi SIMOLA Pada Smartphone Android

Gambar di atas menunjukan tampilan menu laporan ketika admin ingin melihat hasil rekap data siapa saja pengguna yang telah masuk menggunakan ruangan laboratorium komputer.

\section{Tampilan LCD}

Tampilan LCD pada saat kondisi alat baru pertama kali di nyalakan dan melakukan proses inisialisasi memastikan semua komponen terhubung dengan baik.

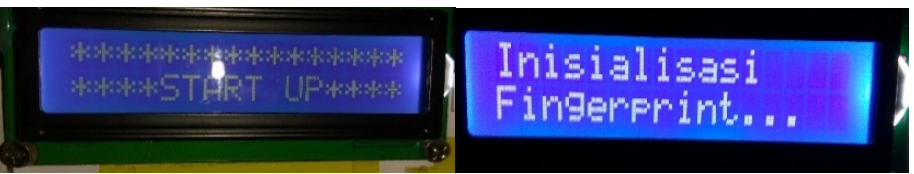

Gambar 10. Tampilan LCD Pada Saat Alat Pertama Kali Di Nyalakan

Tampilan LCD pada saat kondisi pintu tertutup menunggu pembukaan kunci pintu dari luar laboratorium komputer.

\section{Masukan jari}

Gambar 11. Tampilan LCD Pada Saat Menunggu Input Sidik Jari Untuk Membuka Pintu

Tampilan LCD pada saat kondisi pintu berhasil dibuka dengan menempelkan sidik jari yang sudah terdaftar.

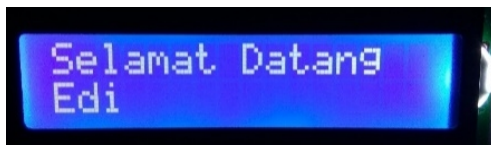

Gambar 12. Tampilan LCD Pada Saat Pintu Berhasil Di Buka

Tampilan LCD pada saat kondisi pintu tertutup dan tidak berhasil di buka karena sidik jari tidak terdaftar

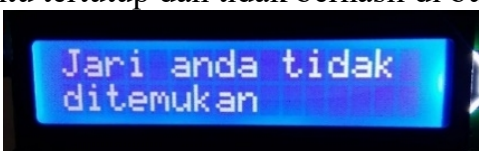

Gambar 13. Tampilan LCD Pada Saat Pintu Tidak Berhasil Di Buka

Tampilan LCD pada saat kondisi pintu di buka melalui tombol yang ada di dalam ketika ruangan digunakan.

\section{PINTU DIBUKA}

Gambar 14. Tampilan LCD Pada Saat Pintu Di Buka dari Dalam Ruangan

Tampilan hasil objek gambar manusia yang di tangkap oleh camera

ELKOM Vol. 12, No. 2, Desember 2019: $15-21$ 
9

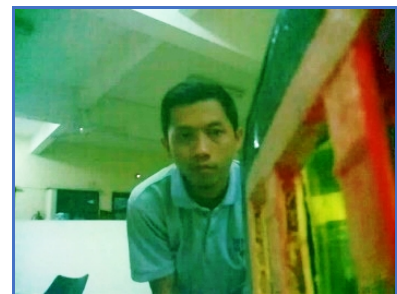

Gambar 15. Hasil Objek Gambar Deteksi Camera

Tampilan pesan notifikasi pada Smartphone Admin pada saat camera mendeteksi ada penyusup atau objek manusia yang tertangkap.



Gambar 16. Hasil Tampilan Pesan Notifikasi Pada Smartphone Admin Laporan data pengguna alat dan laboratorium komputer

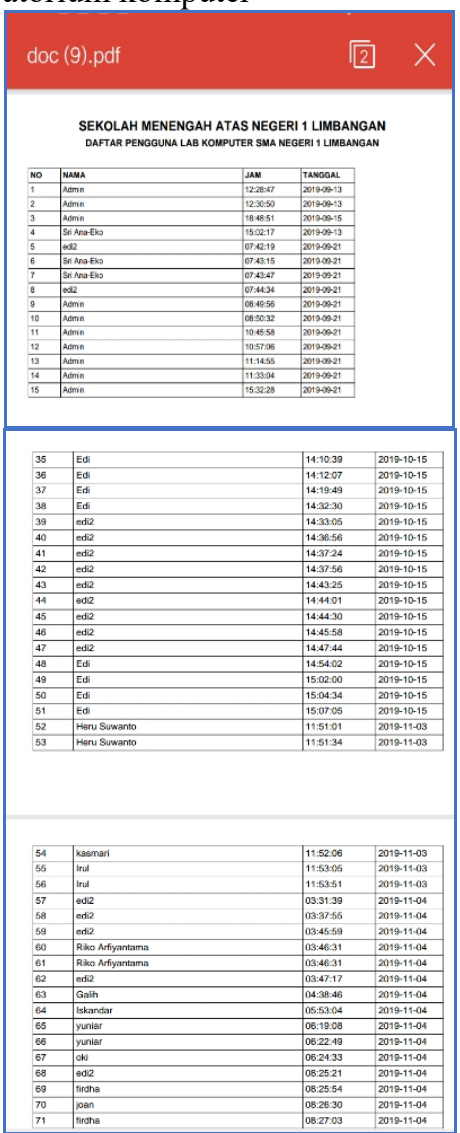

Gambar 17. Hasil Download Laporan Pengguna SIMOLA

Hasil Akhir produk dari prototype alat sistem keamanan SIMOLA 


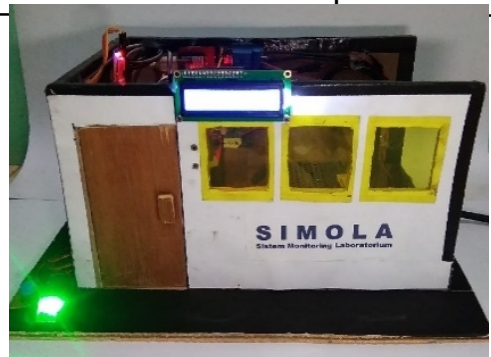

Gambar 18. Hasil Akhir Produk prototype SIMOLA

Sistem keamanan ruangan berbasis raspberry pi ini digunakan untuk mengatasi masalah sistem keamanan lama yang masih dilakukan secara manual dan kurang aman karena masih menggunakan kunci pintu manual dalam akses penggunaan ruang laboratorium komputer. Dengan sistem ini admin/user hanya perlu membuka ruangan menggunakan sidik jari masing-masing yang telah di daftarkan pada alat terlebih dahulu, maka pintu otomatis akan terbuka dan admin/user dapat menggunakan ruang laboratorium komputer. Sehingga tidak semua orang yang tidak berkepentingan dapat membuka pintu dan bebas keluar masuk menggunakan ruangan laboratorium komputer tersebut.

\section{Pengujian Sistem Kerja Alat}

Berikut adalah tabel pengujian sistem kerja yang dilakukan oleh 10 orang pengguna SIMOLA pada semua sensor dengan sesuai standard operasional penggunaan dan pengujian deteksi semua sensor yang terdapat pada alat tersebut.

Tabel 3. Pengujian sistem kerja alat SIMOLA sesuai prosedur penggunaan

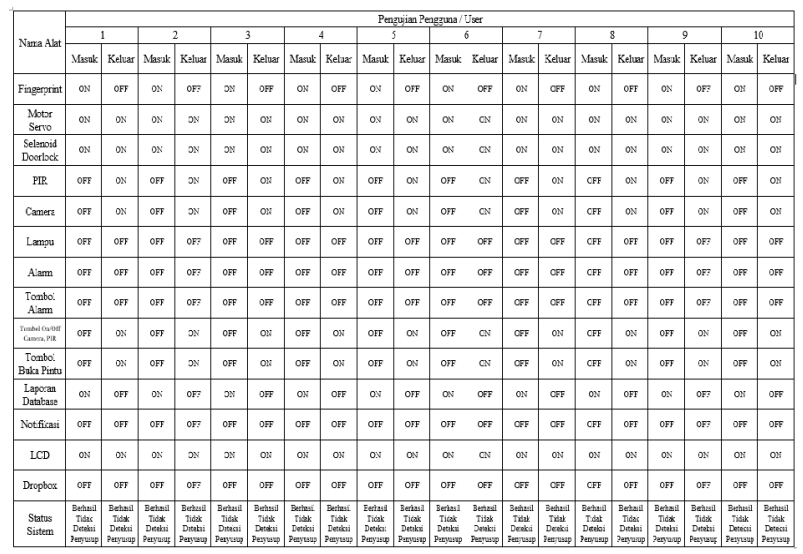

Tabel 4. Pengujian sistem kerja alat SIMOLA deteksi semua sensor

\begin{tabular}{|c|c|c|c|c|c|c|c|c|c|c|}
\hline \multirow{3}{*}{ Nama Alat } & \multicolumn{10}{|c|}{ Pengujian Pengguma / User } \\
\hline & 1 & 2 & 3 & 4 & 5 & 6 & 7 & 8 & 9 & 10 \\
\hline & \begin{tabular}{|l|} 
Masuk \\
\end{tabular} & Masuk & Masuk & Masuk & Masuk & Masuk & Masuk & Masuk & Masuk & \begin{tabular}{|l|} 
Masuk \\
\end{tabular} \\
\hline Fingerprint & OFF & OFF & OFF & OFF & OFF & OFF & OFF & OFF & OFF & OFF \\
\hline $\begin{array}{l}\text { Motor } \\
\text { Servo }\end{array}$ & OFF & OFF & OFF & OFF & OFF & oFF & OFF & OFF & OFF & OFF \\
\hline $\begin{array}{l}\text { Selenoid } \\
\text { Doorlock } \\
\end{array}$ & ofF & OFF & OFF & OFF & ofF & ofF & ofF & OFF & OFF & OFF \\
\hline PIR & on & on & oN & oN & on & on & on & oN & on & on \\
\hline Camera & on & on & ON & on & on & on & on & on & on & on \\
\hline Lampu & on & oN & ON & oN & oN & on & on & on & on & on \\
\hline Alarm & on & on & on & on & on & on & on & on & on & on \\
\hline $\begin{array}{c}\text { Tombol } \\
\text { Allamm }\end{array}$ & on & on & on & oN & on & oN & on & oN & on & on \\
\hline $\begin{array}{c}\text { Tombol } \\
\text { Oomoff } \\
\text { Oamera. PIR } \\
\end{array}$ & OFF & OFF & OFF & OFF & oFF & OFF & OFF & OFF & OFF & OFF \\
\hline $\begin{array}{c}\text { Tombol } \\
\text { Buka Pintu }\end{array}$ & OFF & oFF & OFF & OFF & OFF & oFF & OFF & OFF & OFF & OFF \\
\hline $\begin{array}{c}\text { Laporan } \\
\text { Database }\end{array}$ & OFF & OFF & OFF & OFF & OFF & ofF & OFF & OFF & OFF & OFF \\
\hline Notifikasi & on & on & ON & oN & on & on & on & oN & on & on \\
\hline LCD & OFF & OFF & OFF & OFF & OFF & OFF & OFF & OFF & OFF & OFF \\
\hline Dropbox & on & on & ON & ON & on & on & on & oN & ON & on \\
\hline $\begin{array}{l}\text { Status } \\
\text { Sistem }\end{array}$ & \begin{tabular}{|c} 
Deschsi \\
Peanuwup
\end{tabular} & $\begin{array}{l}\text { Dedecsi } \\
\text { Penyusup }\end{array}$ & \begin{tabular}{|c|} 
Dediki \\
Penyusupp
\end{tabular} & $\begin{array}{c}\text { Dediksi } \\
\text { Penyusup }\end{array}$ & $\begin{array}{c}\text { Dedidsi } \\
\text { Penyuasp }\end{array}$ & $\begin{array}{c}\text { Dendsi } \\
\text { Penyusup }\end{array}$ & \begin{tabular}{|c|} 
Dedisis \\
Penyusup
\end{tabular} & $\begin{array}{c}\text { Deeski } \\
\text { Penyusup }\end{array}$ & $\begin{array}{c}\text { Dencisi } \\
\text { Penyuuap }\end{array}$ & \begin{tabular}{|c} 
Dendsi \\
Penyusup
\end{tabular} \\
\hline
\end{tabular}


Dari pengujian sesuai dengan standar operasional penggunaan alat seperti yang ditunjukan pada Tabel 3 bahwa hasil yang di dapatkan dari 10 sidik jari yang telah terdaftar pada sistem simola untuk tingkat keberhasilanya adalah $100 \%$, menjelaskan bahwa sistem dapat digunakan dengan baik untuk memenuhi kebutuhan sistem keamanan.

Selain 10 pengguna diminta melakukan pengujian terhadap semua sensor yang terdapat pada alat seperti yang di tunjukan pada Tabel 4 di atas, bahwa telah di dapatkan hasil dengan tingkat keberhasilan 100\%, jadi dapat di ketahui semua sensor dapat bekerja dengan baik.

\section{KESIMPULAN}

Berdasarkan analisa dan hasil perancangan sistem ini, maka dapat ditarik kesimpulan sebagai berikut :

a) Pengujian semua sensor yaitu sensor fingerprint, PIR dan camera dapat bekerja dengan baik sesuai yang diharapkan.

b) Alat dan sistem dapat bekerja secara otomatis mengirimkan notifikasi pada smartphone android pengelola/admin.

c) Dengan di bangunnya alat sistem keamanan simola dapat membatasi akses pengguna ruang laboratorium komputer sehingga penggunaan ruangan lebih terjaga dan terpantau oleh pengelola.

d) Pengelola dapat mengetahui siapa saja user yang menggunakan ruangan dengan melalui data laporan yang dapat di download pada aplikasi simola sesuai dengan gambar 4.15 laporan data pengguna ruang laboraotium.

Hasil dari deteksi gambar yang dihasilkan oleh camera serta pesan notifikasi yang dikirimkan pada smartphone dapat berjalan dengan baik.

\section{DAFTAR PUSTAKA}

[1] M. A. R Febryantahanuji. Z. Mustofa, "Pemetaan Digital Lokasi Sentra Pertanian Dan Perikanan Untuk Menarik Minat Investor Pada Kabupaten Demak Kota Dengan Platform Android," JOINED, vol. 3, no. 1, pp. 43-53, 2018.

[2] L. B. Prianggodo, "Perancangan Object Tracking Robot Berbasis Image Processing Menggunakan Raspberry Pi,” Muhammadiyah Surakarta, 2016.

[3] E. D. W. Muhammad Chamdun, Ardian Fatchur Rochim, "Sistem Keamanan Berlapis Pada Ruangan Rfid (Radio Frequency Identification) Dan Keypad Untuk Membuka Pintu Secara Otomatis," Diponegono Semarang, 2015.

[4] F. D. S. Edi Rakhman, Faisal Candrasyah, RASPBERRY PI - Mikrokontroler Mungil yang Serba Bisa. Yogyakarta: Andi, 2014.

[5] Sugiono, Metode Penelitian Pendidikan. Bandung: Alfabeta, 2016. 